Vol. 4, No. 2, 2018

\author{
Vasyl Olshanskiy ${ }^{1}$, Volodymyr Burlaka ${ }^{2}$, Maksym Slipchenko ${ }^{3}$
}

1. Department of Physics and Theoretical Mechanics, Kharkiv Petro Vasylenko National Technical University of Agriculture, Ukraine, Kharkiv, Alchevskikh str., 44, E-mail: OlshanskiyVP@gmail.com

2. Department of Physics and Theoretical Mechanics, Kharkiv Petro Vasylenko National Technical University of Agriculture, Ukraine, Kharkiv, Alchevskikh str., 44, E-mail: Burlaka2V@ukr.net

3. Department of Physics and Theoretical Mechanics, Kharkiv Petro Vasylenko National Technical University of Agriculture, Ukraine, Kharkiv, Alchevskikh str., 44, E-mail: Slipchenko_M@ukr.net

\title{
FREE OSCILLATIONS OF AN OSCILLATOR WITH NONLINEAR POSITIONAL FRICTION
}

Received: November 23, 2018 / Revised: December 24, 2018 / Accepted: December 26, 2018

(C) Olshanskiy V., Burlaka V., Slipchenko M., 2018

\begin{abstract}
The variations of a system with one degree of freedom in the presence of nonlinear positional friction were considered. The restoring force of the oscillator's elasticity is described by the power function. A nonlinear solution of the Cauchy problem for the case of a power nonlinearity of positional friction were constructed. It is expressed through known periodic Ateb functions, which in recent years have become widespread in the theory of oscillations thanks to the efforts of the Lviv School of Mathematics and Mechanics. Formulas for calculating the displacements of the oscillator in time, as well as the amplitudes and periods of oscillations caused by the initial deviation of the system from the equilibrium position or the initial velocity given to the oscillator in this position were derived. The analytical dependence of the oscillation periods on the amplitude for cases of soft and rigid characteristics of the elastic system was established. It was found that due to the non-linearity of the damping of the system of the amplitudes, it leads to a change in the period of the oscillations of the system during its motion. The period may decrease or increase with oscillation, depending on the value of the indicator of non-linearity in the expression of the restoring force. It is shown, that from the obtained analytical solutions, as separate cases, there were known formulas related to free nonlinear oscillation oscillators without friction or with linear position friction. In order to simplify the using of the obtained solutions, we recommend well-known approximations of the Ateb-functions with the help of elementary functions. Examples of calculations are presented, where comparison of the results obtained with the use of constructed analytical solutions and numerical integration of the equation of oscillation on a computer is carried out. The good consistency of numerical results obtained in different ways is noted.
\end{abstract}

Keywords: dissipative oscillator, nonlinear positional friction, free nonlinear oscillations, periodic Ateb-functions.

\section{Introduction}

Despite the existence of many publications, the theory of nonlinear oscillations remains an important area of research in applied mechanics. This is confirmed by modern publications on the free fluctuations of conservative systems, which are included in the literature list in the article [1]. The using of mathematical models of the modern theory of Ateb-function opens up new possibilities for the analysis of oscilation processes. This also applies to oscillations of dissipative nonlinear systems, which are less elucidated in the literature and require further research.

\section{Problem Statement}

The purpose of this article is to develop a mathematical model of free oscillations of a oscillator with nonlinear position friction when the frictional force on certain areas of motion is a power function of the 


\section{Free Oscillations of an Oscillator with Nonlinear Positional Friction}

displacement of the system. In this formulation the problem becomes essentially nonlinear, and its analytical solution is associated with the use of special functions.

\section{Analysis of modern information sources}

The theory of free oscillation oscillators with linear-position friction is highlighted in [2, 3]. Later in $[4,5]$, we also considered oscillations of the stoichiometric systems, which additionally, in addition to positional friction, still had viscous or dry coulomb friction, that is, it was a matter of combining energy dissipation. Free oscillations of the systems of variable mass with positional friction are described in [6, 7]. In the first of these papers [6] it was assumed that the change in mass in time passes according to the linear law, and in the second [7] - for the quadratic. But all these works are devoted to the analysis of the action of the force of linear positional friction, when it is in certain areas of motion is proportional to the displacement of the system. In case of violation of such dependence, the obtained results lose their validity and require generalization. This is the reason for the purpose of this work.

\section{Statement of purpose and tasks of research}

The main goal is to construct a solution of the equation of free oscillator oscillator with nonlinear positional friction. For its realization the following tasks are set: 1) compose the equation of motion of an oscillator; 2) build its analytical solution using Ateb-functions; 3) find the dependence of the oscillation period on the initial deviation or the initial velocity; 4) make calculations to check the adequacy of the constructed solutions.

\section{Main material presentation}

Dependence of the force of elasticity $F(x)$ from the displacement of the system $x(t)$ describe by expression:

$$
F(x)=(c+\Delta c \cdot \operatorname{sign} x \cdot \operatorname{sign} \dot{x})|x|^{v} \operatorname{sign}(x),
$$

where $c, \Delta c$ - oscillator stiffness characteristics; $v>0$ - nonlinearity indicator; the dot denotes $x$ the derivative with respect to $t$.

Graphically, the dependence $F(x)$ is given in Fig. 1.

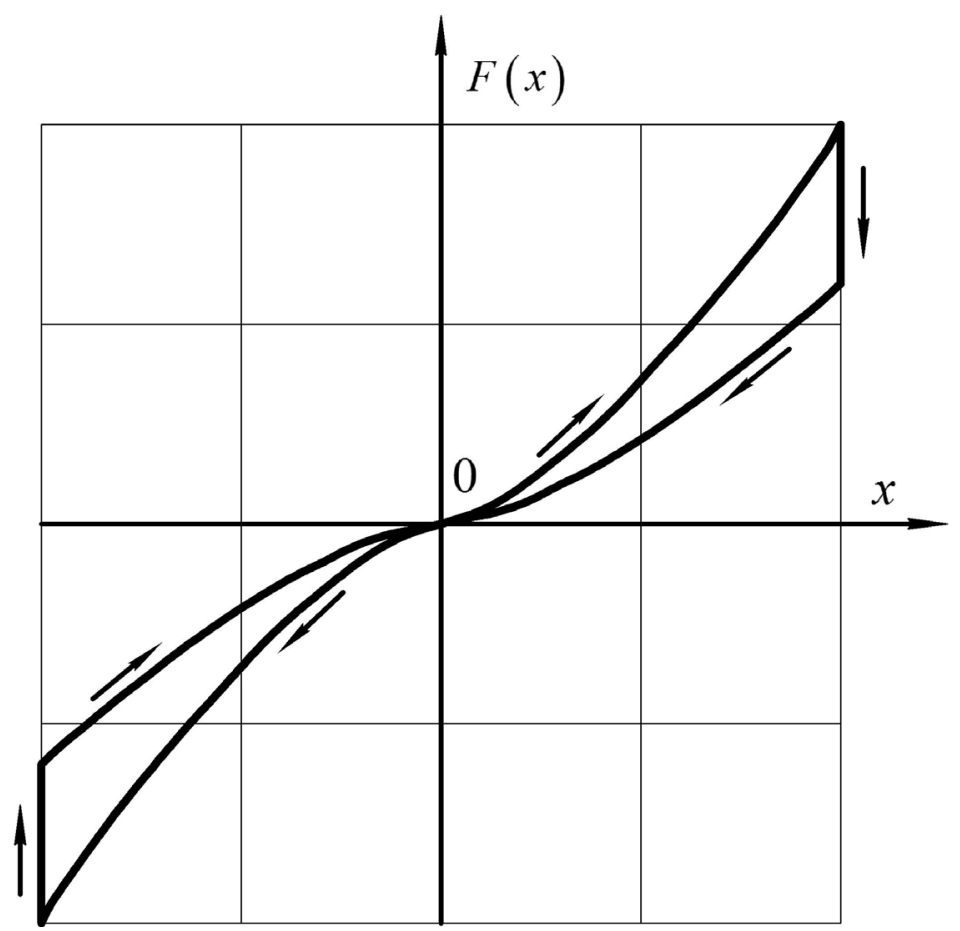

Fig. 1. Dependence $F(x)$ on the increase and decrease of $|x|$ 


\section{Vasyl Olshanskiy, Volodymyr Burlaka, Maksym Slipchenko}

At first, let us consider the free oscillations, under the action of force $F(x)$, caused by the initial deviation $x=a_{0}$ from the position of equilibrium $x=0$. Moving the oscillator in time $x(t)$ at intervals $t \in[0 ; t]$, when it moves to the equilibrium position $(x>0, \dot{x}<0)$ is described by the differential equation:

$$
M \ddot{x}=F(x)=0 \text { or } M \ddot{x}+c_{1} x^{v}=0,
$$

where $c_{1}=c-\Delta c ; M-$ mass of the oscillator.

Initial conditions for Eq. (1) accept:

$$
x(0)=a_{0} \quad \text { or } \dot{x}(0)=0 .
$$

The Cauchy problem, represented by expressions Eqs. (1) and (2), is analytically solved in [8]. This solution looks like:

$$
\dot{x}=-\sqrt{\frac{2 c_{1}}{M(v+1)}} \sqrt{a_{0}^{v+1}-x^{v+1}} ; x(t)=a_{0} \mathrm{Ca}\left(v, 1, \frac{v+1}{2} \tau\right),
$$

where $\tau=a_{0}^{\frac{v-1}{2}} \sqrt{\frac{2 c_{1}}{M(v+1)}} t ; \mathrm{Ca}\left(v, 1, \frac{v+1}{2} \tau\right)$ - periodic Ateb cosine.

It should be noted that earlier periodic Ateb-functions in the theory of mechanical oscillations were used in [9-12] and in other publications, which considered not only free oscillations, but also forced, perturbed by periodic external loads.

From Eq. (3) it follows, that the position $x=0$ when $t=t_{0}$, the oscillator runs at a velocity:

$$
\dot{x}=\dot{x}_{0}=-\sqrt{\frac{2 c_{1}}{M(v+1)}} a_{0}^{\frac{v+1}{2}} .
$$

To calculate the value of $t_{0}$ we have the relation:

$$
t_{0}=\sqrt{\frac{M(v+1)}{2 c_{1}}} \cdot a_{0}^{\frac{1-v}{2}} \mathrm{I}
$$

where $\mathrm{I}=\int_{0}^{1} \frac{d u}{\sqrt{1-u^{v+1}}}$

This integral is expressed in terms of the gamma-function $\Gamma(z)$ that is tabulated in $[13,14]$ and is given by the formula [15]:

$$
\mathrm{I}=\frac{\sqrt{\pi}}{v+1} \cdot \frac{\Gamma\left(\frac{1}{v+1}\right)}{\Gamma\left(\frac{v+3}{2 v+2}\right)} .
$$

Therefore, Eq. (4) takes the form:

$$
t_{0}=\frac{\sqrt{\pi}}{\sqrt{2}} \cdot \frac{\Gamma\left(\frac{1}{v+1}\right)}{\Gamma\left(\frac{v+3}{2 v+2}\right)} \sqrt{\frac{M}{c_{1}(v+1)}} \cdot a_{0}^{\frac{1-v}{2}} .
$$
following:

In the case of linear friction, when $v=1$, the above-mentioned collisions are reduced to the

$$
\dot{x}=-\sqrt{\frac{c_{1}}{M}} a_{0} ; x(t)=a_{0} \cos \left(\sqrt{\frac{c_{1}}{M} t}\right) ; t_{0}=\frac{\pi}{2} \sqrt{\frac{M}{c_{1}}},
$$

which is in agreement with [2]. 


\section{Free Oscillations of an Oscillator with Nonlinear Positional Friction}

Further motion of the oscillator from the position $x=0 \quad(x<0, \dot{x}<0)$ is described by the differential equation:

$$
M \ddot{x}+c_{2}|x|^{v} \operatorname{sign} x=0 \text { or } M \ddot{y}+c_{2} y^{v}=0,
$$

where $y(t)=-x(t) ; t \in\left[t_{0} ; t_{1}\right] ; c_{2}=c+\Delta c$.

As initial conditions to Eq. (5) we accept:

$$
y\left(t_{0}\right)=0 ; \dot{y}\left(t_{0}\right)=\dot{y}_{0}=\sqrt{\frac{2 c_{1}}{M(v+1)}} \cdot a_{0}^{\frac{v+1}{2}} .
$$

The first integral of equation Eq. (5) satisfying conditions Eq. (6), has the form:

$$
\dot{y}=\sqrt{\dot{y}_{0}^{2}-\frac{2 c_{2}}{M(v+1)} y^{v+1}}=\sqrt{\frac{2}{M(v+1)}} \cdot \sqrt{c_{1} a_{0}^{v+1}-c_{2} y^{v+1}} .
$$

From this it follows, that the amplitude deviation of the system $a_{1}$ at the end of the first magnitude of oscillation, when $\dot{y}=0$, is:

$$
x=-a_{1}=-a_{0} \cdot\left(\frac{c_{1}}{c_{2}}\right)^{\frac{1}{v+1}} .
$$

The second integral of equation Eq. (5) is expressed by the periodic Ateb-sinus product:

$$
y(t)=-x(t)=a_{1} \cdot \mathrm{Sa}\left(v, 1, \frac{v+1}{2} \xi\right),
$$

where $\xi=\sqrt{\frac{2 c_{2}}{M(v+1)}} a_{1}^{\frac{v-1}{2}}\left(t-t_{0}\right)$.

The end of the first magnitude comes at:

$$
\operatorname{Sa}\left(v, 1, \frac{v+1}{2} \xi\right)=1 .
$$

The root of this equation $\xi=\mathrm{I}$ determines the stop time of the oscillator:

$$
t_{1}=t_{0}+\frac{\sqrt{\pi}}{\sqrt{2}} \cdot \frac{\Gamma\left(\frac{1}{v+1}\right)}{\Gamma\left(\frac{v+3}{2 v+2}\right)} \sqrt{\frac{M}{c_{2}(v+1)}} \cdot a_{1}^{\frac{1-v}{2}} .
$$

Thus, the duration of the first magnitude of oscillations is:

$$
t_{1}=\frac{\sqrt{\pi}}{\sqrt{2}} \cdot \frac{\Gamma\left(\frac{1}{v+1}\right)}{\Gamma\left(\frac{v+3}{2 v+2}\right)} \sqrt{\frac{M}{v+1}}\left(\frac{1}{\sqrt{c_{1}}} a_{0}^{\frac{1-v}{2}}+\frac{1}{\sqrt{c_{2}}} a_{1}^{\frac{1-v}{2}}\right)
$$

and the amplitude deviation of the system is: $x\left(t_{1}\right)=-a_{1}=-a_{0} \cdot\left(\frac{c_{1}}{c_{2}}\right)^{\frac{1}{v+1}}$.

If $v=1$, then, in accordance with (7), (9):

$$
t_{1}=\frac{\pi}{2} \cdot \sqrt{M}\left(\frac{1}{\sqrt{c_{1}}}+\frac{1}{\sqrt{c_{2}}}\right) ; a_{1}=a_{0} \sqrt{\frac{c_{1}}{c_{2}}} .
$$

These results were obtained earlier in the theory of linear-position friction in [2], where time $t_{1}$ does not depend on the initial deviation of the oscillator, which is characteristic of linear systems. 


\section{Vasyl Olshanskiy, Volodymyr Burlaka, Maksym Slipchenko}

The above solutions are suitable for calculating the second and subsequent magnitudes of the oscillator, but we must specify the pre-computational amplitudes for system deviations from equilibrium positions. So, for a second scale, instead of $a_{0}$ in the formula, we must take $a_{1}$. At the end of this magnitude, the amplitude of the deviation $a_{2}$, taking into account Eq. (7), becomes:

$$
a_{2}=a_{1} \cdot\left(\frac{c_{1}}{c_{2}}\right)^{\frac{1}{v+1}}=a_{0} \cdot\left(\frac{c_{1}}{c_{2}}\right)^{\frac{2}{v+1}} .
$$

It should be used in the calculation of the third scale of oscillations, etc.

To calculate the first period of oscillations, we obtain the formula:

$$
t_{2}=T_{1}=\frac{\sqrt{\pi}}{\sqrt{2}} \cdot \frac{\Gamma\left(\frac{1}{v+1}\right)}{\Gamma\left(\frac{v+3}{2 v+2}\right)} \sqrt{\frac{M}{v+1}}\left(\frac{1}{\sqrt{c_{1}}} a_{0}^{\frac{1-v}{2}}+\frac{1}{\sqrt{c_{1}}} a_{1}^{\frac{1-v}{2}}+\frac{1}{\sqrt{c_{2}}} a_{1}^{\frac{1-v}{2}}+\frac{1}{\sqrt{c_{2}}} a_{2}^{\frac{1-v}{2}}\right) .
$$

As we see, when $v \neq 1$, the period depends on the initial deviation of the system from the equilibrium position. In the case of a soft, elastic characteristic of the system $(0<v<1)$, increasing of $a_{0}$ leads to increase of $T_{1}$, and for the rigid characteristics $(v>1)$ we have the opposite tendency.

Summarizing the results obtained, we arrive at the conclusion that in the presence of nonlinear position friction, the change in the amplitudes of free oscillations of the oscillator passes by the law of geometric progression and is described by the expression:

$$
a_{n}=a_{0} \cdot\left(\frac{c_{1}}{c_{2}}\right)^{\frac{2 n}{v+1}}, n=1,2, \ldots,
$$

where the denominator of progression $q=\left(c_{1} / c_{2}\right)^{2 /(v+1)}$ depends on the index of power nonlinearity $v$.

The period of oscillation also depends on the number of the cycle and its calculation is reduced to the formula:

$$
T_{n}=\frac{\sqrt{\pi}}{2} \cdot \frac{\Gamma\left(\frac{1}{v+1}\right)}{\Gamma\left(\frac{v+3}{2 v+2}\right)} \sqrt{\frac{M}{v+1}}\left(\frac{1}{\sqrt{c_{1}}} a_{n-1}^{\frac{1-v}{2}}+\frac{1}{\sqrt{c_{1}}} a_{n}^{\frac{1-v}{2}}+\frac{1}{\sqrt{c_{2}}} a_{n}^{\frac{1-v}{2}}+\frac{1}{\sqrt{c_{2}}} a_{n+1}^{\frac{1-v}{2}}\right) .
$$

Let's consider further free oscillation oscillator when giving it to the position $x=0$ of the initial velocity $v_{0}$ (instantaneous impulse). We will solve the first differential equation in Eq. (5) under initial conditions:

$$
x(0)=0 ; \dot{x}(0)=v_{0} .
$$

By analogy with the previous one, we obtain:

$$
\dot{x}=\sqrt{v_{0}^{2}-\frac{2 c_{2}}{M(v+1)} x^{v+1}} ; x(t)=a_{0}^{*} \cdot \mathrm{Sa}\left(v, 1, \frac{v+1}{2} \eta\right),
$$

where $a_{0}^{*}=\left(\frac{M v_{0}^{2}}{2} \frac{v+1}{c_{2}}\right)^{\frac{1}{v+1}} ; \eta=\left(a_{0}^{*}\right)^{\frac{v-1}{2}} \sqrt{\frac{2 c_{2}}{M(v+1)}} \cdot t$.

Expressions (10) describe the process of removing the oscillator from the equilibrium position. The oscillator stops at $t=t_{*}$, reaching the amplitude deviation $x\left(t_{*}\right)=a_{0}^{*}$. A stop will happen when:

$$
\mathrm{Sa}\left(v, 1, \frac{v+1}{2} \eta\right)=1 \text {. }
$$




\section{Free Oscillations of an Oscillator with Nonlinear Positional Friction}

Since the root of this equation $\eta=\mathrm{I}$, the stopping time is determined by the formula:

$$
t_{*}=\frac{\sqrt{\pi}}{2} \cdot \frac{\Gamma\left(\frac{1}{v+1}\right)}{\Gamma\left(\frac{v+3}{2 v+2}\right)} \sqrt{\frac{M}{(v+1) c_{2}}}\left(a_{0}^{*}\right)^{\frac{1-v}{2}} .
$$

In the case of linear position friction $(v=1)$ :

$$
a_{0}^{*}=\sqrt{\frac{M v_{0}^{2}}{c_{2}}} ; t_{*}=\frac{\pi}{2} \sqrt{\frac{M}{c_{2}}},
$$

so $t_{*}$ does not depend on $v_{0}$.

A further movement of the oscillator will be caused by the initial deviation $x=a_{0}^{*}$, that was considered earlier. Thus, the second variant of the initial conditions in the end is reduced to the first option.

\section{Numerical results}

Example 1. In order to make calculations we accept: $M=5 \mathrm{~kg} ; c=4900 \mathrm{~N} / \mathrm{m} ; \Delta c=0,05 \cdot c$; $v=0,5 ; a_{0}=0,02 \mathrm{~m}$. The specified numerical data corresponds to: $c_{1}=4655 \mathrm{~N} / \mathrm{m} ; c_{2}=5145 \mathrm{~N} / \mathrm{m}$; $\Gamma(2 / 3) \approx 1,35412 ; \Gamma(7 / 6) \approx 0,92772 ; t_{0}=0,01841 s ; a_{1} \approx 0,01871 m ; t_{1}=0,03563 s$. The values of periodic Ateb-functions are calculated using approximations [8]:

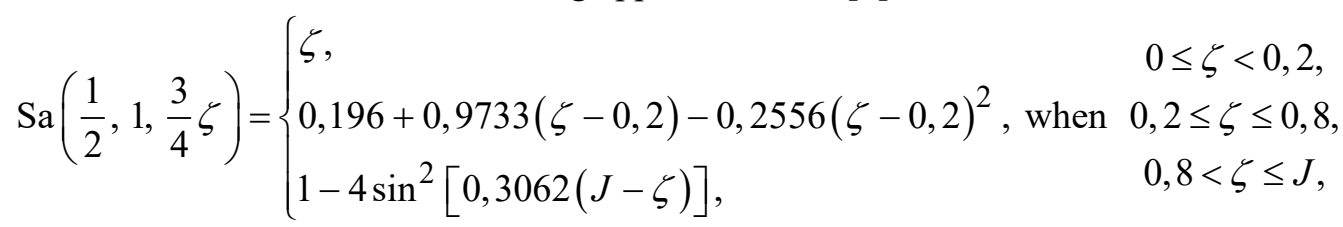

where $J=1,72474 ; \mathrm{Ca}\left(\frac{1}{2}, 1, \frac{3}{4} \zeta\right)=\mathrm{Sa}\left(\frac{1}{2}, 1, \frac{3}{4}(J-\zeta)\right)$.

Obtained by Eqs. (3), (8) and (11), the dimensionless displacements of the oscillator on its first oscillation at different points in time are shown in Table 1. There, too, for comparison, the value of the corresponding displacements obtained by numerical computer integration of Eqs. (1) and (5).

Table 1

Value of displacements at $v=0,5$

\begin{tabular}{|c|c|c|c|c|c|}
\hline$t / t_{0}$ & $\begin{array}{c}x(t) / a_{0} \\
\text { analit. }\end{array}$ & $\begin{array}{c}x(t) / a_{0} \\
\text { num. integr. }\end{array}$ & $t / t_{0}$ & $\begin{array}{c}x(t) / a_{0} \\
\text { analit. }\end{array}$ & $\begin{array}{c}x(t) / a_{0} \\
\text { num. integr. }\end{array}$ \\
\hline 0,0 & 1,0000 & 1,0000 & 1,1871 & 0,3103 & 0,3097 \\
\hline 0,2 & 0,9555 & 0,9555 & 1,3741 & 0,5721 & 0,5728 \\
\hline 0,4 & 0,8241 & 0,8242 & 1,5612 & 0,7709 & 0,7710 \\
\hline 0,6 & 0,6115 & 0,6122 & 1,7483 & 0,8939 & 0,8939 \\
\hline 0,8 & 0,3317 & 0,3312 & 1,9354 & 0,9355 & 0,9355 \\
\hline 1,0 & 0,0000 & 0,0000 & - & - & - \\
\hline
\end{tabular}

There is good consistency of numerical results obtained by different methods, that is, the analytical method with the use of approximation Eq. (11) gives a fairly high accuracy of calculation.

Information on the change of periods of oscillation is provided in Table. 2

Table 2

The ratio of oscillation periods at $v=0,5$

\begin{tabular}{|c|c|c|c|c|c|}
\hline$n$ & 2 & 3 & 4 & 5 & 6 \\
\hline$T_{n} / T_{1}$ & 0,9672 & 0,9355 & 0,9048 & 0,8751 & 0,8464 \\
\hline
\end{tabular}




\section{Vasyl Olshanskiy, Volodymyr Burlaka, Maksym Slipchenko}

In the case of a soft characteristic of elasticity, the attenuation of amplitudes of oscillations is accompanied by a decrease in their periods.

Example 2. By storing the antecedent output data, we calculate the displacement of an oscillator with a nonlinearity index $v=1,5$, it corresponding to a rigid characteristic of elasticity. For this indicator: $\Gamma(2 / 5) \approx 2,21825 ; \Gamma(0,9) \approx 1,06867 ; t_{0}=0,14339 s ; a_{1} \approx 0,01922 m ; t_{1}=0,28115 s$. We value the periodic Ateb-functions by the approximate formula [8]:

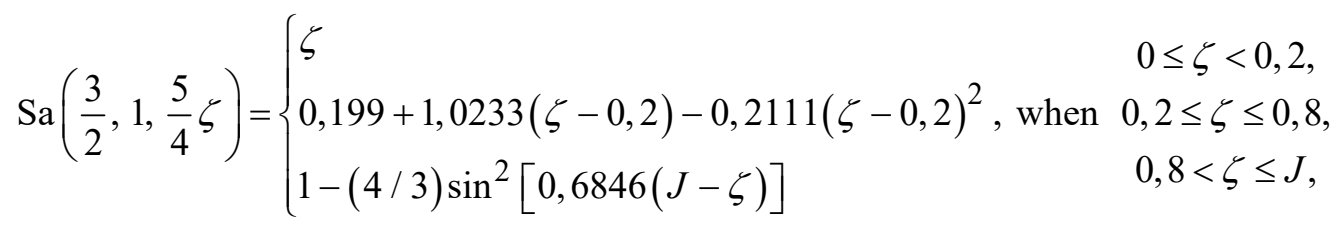

where $J=1,47164 ; \mathrm{Ca}\left(\frac{3}{2}, 1, \frac{5}{4} \zeta\right)=\mathrm{Sa}\left(\frac{3}{2}, 1, \frac{5}{4}(J-\zeta)\right)$.

The results obtained using formulas (3), (8) and (12) are written in Table 3. For comparison, the values of displacements of the oscillator, to which the numerical compomaterial integration of equations (1) and (5) leads, is also indicated there.

Table 3

Value of displacements at $v=1,5$

\begin{tabular}{|c|c|c|c|c|c|}
\hline$t / t_{0}$ & $\begin{array}{c}x(t) / a_{0} \\
\text { analit. }\end{array}$ & $\begin{array}{c}x(t) / a_{0} \\
\text { num. integr. }\end{array}$ & $t / t_{0}$ & $\begin{array}{c}x(t) / a_{0} \\
\text { analit. }\end{array}$ & $\begin{array}{c}x(t) / a_{0} \\
\text { num. integr. }\end{array}$ \\
\hline 0,0 & 1,0000 & 1,0000 & 1,2 & 0,2935 & 0,2921 \\
\hline 0,2 & 0,9466 & 0,9466 & 1,4 & 0,5626 & 0,5644 \\
\hline 0,4 & 0,7949 & 0,7949 & 1,6 & 0,7862 & 0,7858 \\
\hline 0,6 & 0,5648 & 0,5667 & 1,8 & 0,9249 & 0,9247 \\
\hline 0,8 & 0,2936 & 0,2924 & 1,9607 & 0,9610 & 0,9608 \\
\hline 1,0 & 0,0000 & 0,0000 & - & - & - \\
\hline
\end{tabular}

Differences in the results of computations by different methods are insignificant, which pitters the probability of analytic solutions and approximations of Ateb-functions.

The results of calculating the variation of oscillation periods are given in Table 4 .

Table 4

The ratio of oscillation periods at $v=1,5$

\begin{tabular}{|c|c|c|c|c|c|}
\hline$n$ & 2 & 3 & 4 & 5 & 6 \\
\hline$T_{n} / T_{1}$ & 1,0202 & 1,0408 & 1,0618 & 1,0833 & 1,1052 \\
\hline
\end{tabular}

In the case of a rigid characteristic of elasticity, the damping of oscillations is accompanied by an increase in their periods.

The change of periods, as well as the amplitudes, takes place according to the law of geometric progression, whose denominator depends on the nonlinearity index $v$.

\section{Conclusions}

In the article an equation of free oscillation motion of oscillator with power nonlinear positional friction is compiled. The equation is obtained for oscillations with one degree of freedom for the case when the elastic force of the oscillator is described by the power function.

The tasks of free oscillation oscillators with nonlinear-position frictions have an analytic discourse, which is expressed through the periodic Ateb-functions.

The periods of oscillation depend on the initial deviation of the system from the equilibrium position or from the initial velocity given to it, which is not the case with linear friction. The fall of the oscillation 


\section{Free Oscillations of an Oscillator with Nonlinear Positional Friction}

amplitudes passes by the law of geometric progression, the denominator of which depends on the nonlinearity indicator. As the nonlinearity index increases, the rate of oscillation decays decreases.

Free oscillations are accompanied not only by the decrease in the amplitudes of oscillations, but also by the change in their periods. In systems with a soft characteristic of elasticity $(0<v<1)$, the fall of amplitudes is accompanied by a decrease in the oscillation periods, and in the case of a rigid characteristic $(v>1)-$ an increase in periods.

In the article examples of numerical calculations with different indicators of nonlinearity are given. The results of calculations, obtained by different methods: analytical and numerical, have good convergence. For the examples given, the difference in results does not exceed one per cent. This indicates the adequacy of the constructed analytical solutions. In the given examples, the discrepancy in the results does not exceed one percent. This indicates the adequacy of the constructed analytical solutions.

\section{References}

[1] L. Cveticanin, T. Pogany, "Oscillator with a sum of noninteger-order nonlinearities", Journal of Applied Mathematics, vol. 2012, pp. 1-20, 2012. doi:10.1155/2012/649050.

[2] V. L. Biderman, Teoriya mehanicheskih kolebaniy [Theory of mechanical oscillations]. Moscow, Russia: Vysshaya shkola Publ., 1980. [in Russian].

[3] N. G. Suryaninov, A. F. Dashchenko, and P. A. Belous, Teoriticheskie osnovyi dinamiki mashin [Theoretical foundations of machine dynamics]. Odessa, Ukraine: OGPU, 2000. [in Russian].

[4] V. P. Olshanskiy, etc., Kolivannya dysypatyvnykh ostsyliatoriv [Fluctuations of dissipative oscillators]. Kharkiv, Ukraine: Mis'kdruk Publ., 2015. [In Ukrainian].

[5] V. P. Olshanskiy, etc., Dynamika dysypatyvnykh ostsyliatoriv [Dynamics of dissipative oscillators]. Kharkiv, Ukraine: Mis'kdruk Publ., 2016. [In Ukrainian].

[6] V. P. Olshanskiy, S. V. Olshanskiy, "Nestatsionarnyie kolebaniya mehanicheskoy sistemy lineynoperenmennoy massy s kombinirovannyim treniem" [Unsteady oscillations of the mechanical system of linear-variable mass with combined friction], Visnik HNTUSG: Problemi nadiynosti mashin ta zasobiv mehanizatsiyi silskogospodarskogo virobnitstva [Bulletin of KhNTUAC: Problems of reliability of machines and means of mechanization of agricultural production], vol. 151, pp. 324-333, 2014. [in Russian].

[7] V. P. Olshanskiy, S. V. Olshanskiy, "Vilni kolivannya ostsilyatora zminnoyi masi z pozitsiynim tertyam" [Free oscillations of the variable mass oscillator with positional friction], Vibratsii v tekhnitsi ta tekhnolohiiakh [Vibrations in technique and technologies], vol. 2 (78), pp. 27-33, 2015. [in Ukrainian].

[8] V. P. Olshanskiy, S. V. Olshanskiy, "Pro ruh ostsilyatora zi stepenevoyu harakteristikoyu pruzhnostI" [On the motion of an oscillator with a power characteristic of elasticity], Vibratsii v tekhnitsi ta tekhnolohiiakh [Vibrations in technique and technologies], vol. 3 (86), pp. 34-40, 2017. [in Ukrainian].

[9] B. I. Sokil, "Pro zastosuvannya Ateb-funktsiy dlya pobudovi rozv'yazkiv deyakih rivnyan, yaki opisuyut neliniyni kolivannya odnovimirnih seredovisch" [On the application of Ateb-functions for construction of solutions of some equations describing nonlinear oscillations of one-dimensional media], Dopovidi Natsionalnoyi akademiy nauk Ukrayini [Reports of the National Academy of Sciences of Ukraine], vol. 1, pp. 55-58, 1997. [in Ukrainian].

[10] V. V. Gritsik, M. A. Nazarkovich, "Matematichni modeli algoritmiv i realizatsiya Ateb-funktsiy" [Mathematical models of algorithms and implementation of Ateb-functions], Dopovidi Natsionalnoyi akademiy nauk Ukrayini [Reports of the National Academy of Sciences of Ukraine], vol. 12, pp. 37-42, 2007. [in Ukrainian].

[11] I. V. Kuzio, T.-N. M. Vankovich, and Ya. A. Zinko, Teoretichna mehanika. Dinamika. Kn.1 [Theoretical mechanics. Dynamics. B.1]. Lviv, Ukraine: Rastr-7 Publ., 2012. [In Ukrainian].

[12] P. Ya. Pukach, Yakisni metodi doslidzhennya neliniynih kolivanih sistem [Qualitative methods for investigating nonlinear oscillate systems]. Lviv, Ukraine: Lviv Polytechnic Publishing House, 2014. [In Ukrainian].

[13] M. Abramovits, I. Stigan, Spravochnik po spetsialnyim funktsiyam (s formulami, grafikami $i$ matematicheskimi tablitsami) [Handbook of special functions (with formulas, graphs and mathematical tables)]. Moscow, Russia: Nauka Publ., 1979. [in Russian].

[14] E. Yanke, F. Elde, and F. Lesh, Spetsialnyie funktsii [Special functions]. Moscow, Russia: Nauka Publ., 1977. [in Russian].

[15] A. P. Prudnikov, Yu. A. Bryikov, O. I. Marichev, Integraly i ryady. Elementarnyie funktsii [Integrals and rows. Elementary functions]. Moscow, Russia: Nauka Publ., 1981. [in Russian]. 